\title{
A QUESTÃO DO HUMANO: ENTRE O HUMANISMO E O PÓS-HUMANISMO
}

\author{
Cecília de Sousa Neves ${ }^{1}$ \\ Universidade Federal de Uberlândia (UFU)
}

\begin{abstract}
RESUMO:
No registro do contexto tecnocientífico contemporâneo o outrora insuspeito antropocentrismo ontológico que embasou a concepção humanista de homem parece vacilar. O objetivo deste artigo é expor alguns elementos e direcionamentos importantes para a compreensão do modo como o pensamento pós-humanista, que reúne intérpretes deste contexto, rearticula os termos da pergunta antropológico-filosófica acerca do entendimento das noções de humanidade e de ser humano.
\end{abstract}

PALAVRAS-CHAVE: Antropocentrismo; Humanismo; Pós-humanismo; Ser humano.

\section{THE ISSUE OF HUMAN: BETWEEN HUMANISM AND POSTHUMANISM}

\begin{abstract}
:
In the record of contemporary techno-scientific context the once unsuspected ontological anthropocentrism that based the humanist conception of man seems to vacillate. The purpose of this article is to present some of the elements and guidelines for understood the way that the posthumanist thought, which is compost by interpreters of this context, rearticulates the terms of the anthropological-philosophical question about the understanding of the notions of humanity and human being.
\end{abstract}

KEYWORDS: Anthropocentrism; Humanism; Post-humanism; Human being.

A reflexão acerca do estatuto do ser humano é, sem dúvida, o núcleo em torno do qual a história do pensamento orbitou. De fato, várias antropologias subjazem as filosofias, religiões e ciências em seus esforços de explicar a gênese, o significado e o destino do fenômeno humano. Visto

\footnotetext{
${ }^{1}$ Mestre em filosofia pela Universidade Federal de Uberlândia (UFU), Minas Gerais Brasil. E-mail: cecilianeves2003@yahoo.com.br
} 
que o pensar mediante dicotomias constitui uma constante na tradição ocidental, é inevitável que tais esforços de autocompreensão sejam atravessados por uma série de dualismos. Razão pela qual nos é familiar as oposições entre corpo e espírito, instinto e consciência, emoção e razão, natureza e cultura e, por conseguinte, ciências naturais e humanidades ${ }^{2}$. Segundo o antropólogo inglês Tim Ingold, o fator decisivo para a formatação de uma perspectiva acerca do que é o ser humano dependerá em cada autor (ou corrente) da centralidade que se confere aos termos da expressão "natureza humana": se a ênfase recai sobre a noção de natureza, conforme o paradigma das ciências naturais, é a animalidade o aspecto central do fenômeno humano, sendo este considerado, portanto, como uma "pequena província do reino animal"; ao passo que se o acento recai no termo "humano", conforme o paradigma das humanidades e da filosofia, é a espiritualidade, a consciência ou a "aptidão para a cultura" que constitui a qualidade distintiva do humano concebido antes como um "império dentro

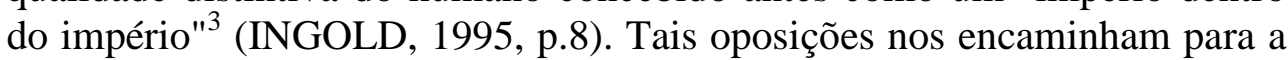
paradoxal concepção ocidental do homem como ser dilacerado, dividido entre a condição física de sua animalidade e a condição moral de sua humanidade.

A dicotomia humanidade/animalidade é o dogma antropológico fundamental associado ao humanismo (BALIBAR, 1991), isto é, a ideia de que o humano se realiza transcendendo o âmbito da mera animalidade e materialidade. A eminência conferida ao polo humano, cuja natureza específica seria objeto das disciplinas literárias, responsáveis pela educação e formação espiritual do homem, constitui o cerne originário do humanismo, assim como a base da representação do mundo humano como um mundo à parte do restante da natureza. No Discurso sobre a dignidade do homem (1486), o escrito mais representativo do pensamento clássico humanistarenascentista, Pico della Mirandola justifica o significado metafísico e moral do homem como "grande milagre" da criação projetando um possível discurso de Deus para o homem:

Ó Adão, não te demos nem um lugar determinado, nem um aspecto que te seja próprio, nem tarefa alguma específica, a fim de que obtenhas e possuas aquele lugar, aquele aspecto, aquela tarefa que tu seguramente desejares, tudo segundo o teu parecer e a tua decisão. A natureza bem definida dos outros seres é refreada por leis por nós prescritas. Tu, pelo contrário, não constrangido por nenhuma limitação, determiná-la-ás para ti,

\footnotetext{
${ }^{2} \mathrm{O}$ diagnóstico e análise da amplitude do abismo criado entre as ciências e as humanidades é o tema da obra de Snow (1959), através da qual se tornou célebre o conceito de "duas culturas".

${ }^{3}$ A famosa passagem de Spinoza, entretanto, visa criticar os insensatos que concebem "os homens na Natureza como um império dentro do império" (SPINOZA, 2010, p. 161). Dessa forma, ele ataca um dos pilares do humanismo moderno.
} 
segundo o teu arbítrio, a cujo poder te entreguei. Coloquei-te no meio do mundo para que daí possas olhar melhor tudo o que há no mundo. Não te fizemos celeste nem terreno, nem mortal nem imortal, a fim de que tu, árbitro e soberano artífice de ti mesmo, te plasmasses e te informasses, na forma que tivesses seguramente escolhido. Poderás degenerar até os seres que são as bestas, poderás regenerar-te até às realidades superiores que são divinas, por decisão do teu ânimo. (MIRANDOLA, 1989, p.52-53).

Percebe-se o núcleo de sentido comum à variedade de filosofias e sistemas específicos concebidos sob a égide do "Humanismo". Trata-se da ideia de que a singularidade do homem consiste na liberdade face aos determinismos em relação aos quais o restante dos animais estão submetidos, em função de uma identidade aberta, isto é, moldável conforme suas escolhas morais. Tal abertura "é exatamente o que possibilita, para um ser livre, com relação ao que é e ao que ele é, a capacidade de pôr fins definidores do que deve ser e o que ele deve ser." (FERRY, 1989, p.243).

Como percebemos na história ocidental da filosofia a justificação desta superioridade dar-se-á, com frequência, através da atribuição de qualidades universais e apriorísticas exclusivas à espécie humana. Estas qualidades, constantemente, assumiram a forma de universais antropológicos ${ }^{4}$. De modo que, esta superioridade será legitimada nos termos de um fundacionismo filosófico, na medida em que a pressuposição de um sujeito como algo que subjaz (subjectum), ou seja, um campo ideal, universal e permanente, enquanto a dimensão especificamente humana, tem como fim fundamentar a inteligibilidade do real. Este substrato será elaborado de diversas maneiras ao longo da tradição filosófica ${ }^{5}$, a ponto de

\footnotetext{
${ }^{4}$ Especialmente em relação aos predicados associados à racionalidade: linguagem, aptidão para a cultura etc.

${ }^{5}$ A busca de um princípio metafísico centrado no humano será elaborada como "eidos" em Platão, "ousia" em Aristóteles, "esse" em Santo Tomás de Aquino, o "cogito ergo sum" cartesiano, o "sujeito transcendental" de Kant, a "razão" ou o "espírito" em Hegel e, segundo Heidegger, a história desta busca culmina no conceito de "vontade de poder" nietzschiano. A subjetividade moderna arquitetada por Descartes e fundamentada no cogito enquanto o primeiro princípio da filosofia (DESCARTES, 1996, p.38), deixa entrever alguns traços gerais desta "metafísica da subjetividade" aqui tomada como núcleo da compreensão humanista de ser humano. Segundo esta, o estatuto superior do homem corresponde à sua capacidade de mediar com a realidade externa e transcendê-la, apreendendo-a conceitualmente. Por ser dotado de consciência e razão, ele se eleva como o único ser capaz de representar o mundo de modo exato mediante um espelhamento mental da realidade, ou seja, através da tradução de aspectos do mundo em imagens e conceitos claros e distintos, universais e apriorísticos. O sujeito, neste sentido, é um conceito filosófico-metafísico que descreve aquele que é consciente de seus pensamentos e responsável pelos seus atos, pois enquanto senhor absoluto de si é também o agente e a unidade substancial à qual se remetem todas as suas representações e ações. Ele é uno, simples, permanente, autorreferenciado. Compreendido nestas bases diz respeito a um
} 
constituir o paradigma da ortodoxia filosófica assim formulado por Kant na terceira crítica:

\begin{abstract}
Enquanto único ser na Terra que possui entendimento [Verstand], por conseguinte uma faculdade de voluntariamente colocar a si mesmo fins, ele [o homem] é corretamente denominado senhor da natureza, e se considerarmos esta como um sistema teleológico, o último fim da natureza segundo a sua destinação. (KANT, 2012, p.306).
\end{abstract}

Este entendimento também constitui o referencial globalizado acerca da identidade humana, expresso no artigo primeiro da Declaração universal dos direitos humanos: "Todos os seres humanos nascem livres e iguais em dignidade e direitos. São dotados de razão e consciência e devem agir em relação uns aos outros com espírito de fraternidade." (ONU).

No entanto, resta claro que a ruína deste modelo de subjetividade já se configura um evento histórico real $^{6}$ com múltiplas raízes ${ }^{7} \mathrm{e}$ direcionamentos. Importa salientar o impacto da confusão entre a noção filosófica de sujeito e a noção de cunho sociológico-psicológico de indivíduo. Segundo Bendassolli (2002, p.314), o problema surge quando as ciências sociais descrevem o indivíduo concreto atribuindo-lhe características que pertencem ao sujeito metafísico, considerando o indivíduo ${ }^{8}$ um exemplar de um tipo ideal que corresponde à verdadeira

verdadeiro ponto arquimediano, isto é, a referência ou critério fundamental da verdade, assim como a matriz da determinação do significado ideal da "verdadeira natureza humana" em relação à qual todos os indivíduos concretos serão não apenas medidos, mas também subordinados. Ou seja, em todas as instâncias da vida os seres humanos são representados e acabam por se reconhecerem como subjetividade individualizada, foco psicológico unificado de sua biografia, locus de direitos, reivindicações e atos de escolha.

6 Embora, concomitante à dispersão conceitual do "eu" verifiquemos uma espécie de intensificação governamental desta ideia, através de "práticas regulatórias que buscam governar os indivíduos de uma maneira que está, mais do que nunca, ligada àquelas características que o definem como um 'eu'." (ROSE, 2001, p.140-1).

7 "A subjetividade humana é, hoje, mais do que nunca, uma construção em ruínas. Ela já não tinha mesmo jeito, desde as devastadoras demolições dos 'mestres da suspeita': Marx, Freud, Nietzsche, sem esquecer, é claro, Heidegger. A obra de desconstrução iria prosseguir, incansável, a partir de meados do século $\mathrm{XX}$, com as operações de desalojamento do cogito cartesiano efetuadas pela revisão althusseriana de Marx e pela revisão lacaniana de Freud. Depois, com os pós-estruturalistas, Foucault, Deleuze, Derrida, Lyotard, o estrago se tornaria irremediável e irreversível. Sem volta. A point of no return. A questão não é mais, agora, 'quem é o sujeito?', mas 'queremos, ainda, ser sujeitos?', 'quem precisa do sujeito?' (GUZZONI, 1996), 'quem tem nostalgia do sujeito?' e, mais radicalmente, talvez, 'quem vem depois do sujeito?' (CADAVA; CONNOR; NANCY, 1991). Ou ainda, como Maurice Blanchot (1991), a essa última pergunta podemos, talvez cinicamente, nos limitar a retrucar: 'quem mesmo?"' (TADEU, 2009, p.9).

${ }^{8}$ Cujo surgimento podemos acompanhar "por meio dos estudos clássicos de Norbert Elias (Elias, 1982/1993). Em Norbert Elias acompanhamos como o indivíduo, independentemente de ideais metafísicos a priori, se constitui na base de distintas regras socializatórias, que variam ao longo do tempo e em função de grupos sociais concretos. 
condição humana. Analogamente, pode-se dizer que um problema surge na tentativa, também estéril, de interpretar os caminhos, promessas e produtos das tecnociências contemporâneas e, principalmente, o impacto decisivo destes na vida sociocultural e no próprio significado de ser humano, a partir deste mesmo sujeito filosófico tradicional ${ }^{9}$. Razão disso é o fato de que este modelo de sujeito, legitimado nos termos da divisão entre natureza e cultura, bem como entre ciências naturais e humanidades, revela-se como um recurso interpretativo impotente face ao contexto instaurado pelos desenvolvimentos tecnocientíficos contemporâneos. Na medida em que incide sobre todas as instâncias da vida, desde o nascimento até a morte, do corpo à cultura, a tecnologia promove uma complexa hibridação entre homem e artefatos técnicos a ponto de se tornarem indissociáveis. Este movimento de hibridação entre homem e máquina, inevitável e autoevidente, afasta a condição humana de sua suposta pureza ontológica instaurando um questionamento radical da primazia metafísica do humano e do seu direito natural de conquista e domínio do restante da natureza.

Se a retomada da pergunta pelo entendimento do ser humano acompanha as mudanças culturais significativas, em nossa era fundamentalmente tecnológica, essa pergunta é modulada nos termos e possibilidades abertas pela engenharia genética, inteligência artificial, nanotecnologias, técnicas criadoras de realidades virtuais, medicina restauradora, reprodução artificial etc. Porque vivemos em uma época em que "a racionalidade tecnocientífica se tornou uma nova cultura" (FEENBERG, 2003, não paginado), o que significa constatar a onipresença da tecnologia e a predominância dos modos técnicos de pensamento na vida cotidiana, as possíveis contestações das limitações e potencialidades do ser humano devem pressupor, em primeira instância, a rede de arranjos tecnológicos que estruturam a constelação de sentidos e práticas da realidade em que vivemos. É preciso, portanto, partir da liquidação do direito a uma natureza humana fixa e especial e da recolocação do humanismo na agenda de discussão, visto que o homem não é senão "uma invenção cuja recente data a arqueologia de nosso pensamento mostra facilmente. E talvez o fim próximo." (FOUCAULT, 1999, p. 536). Nesse sentido, a pergunta antropológico-filosófica acerca da humanidade, ou ainda, "a identidade última de nosso ser se dissolveria na trama das estruturas que constituem a realidade humana tal como é recolocada pela ciência de nosso tempo." (PARÍS, 2002, p. 26).

Nesta perspectiva, o indivíduo, ao contrário do sujeito, não fundamenta nada, não serve de base para o estabelecimento da verdade dos diversos saberes; ele é circunscrito e tem, digamos assim, uma 'face'" (BENDASSOLLI, 2002, p.314)

${ }^{9}$ Citamos ao menos três exemplos que perturbam intensamente o modelo de identidade humana compreendido nos termos de um tipo perfeito e universal de humanidade: a clonagem, a engenharia genética e as técnicas criadoras de realidade virtual. 
O movimento pós-humanista, que atualmente reúne um conjunto de intérpretes do contexto tecnocientífico atual, busca responder à impotência da categoria do sujeito tradicional em compreender o fenômeno humano, doravante inscrito em um contexto de tensões, integrações e metamorfoses irreversíveis com um outro não-humano, especialmente, o maquínico. Esta resposta é elaborada não em termos de um conceito abstrato, ele mesmo melhorado de ser humano, isto é, que acolhesse os aspectos inéditos da experiência humana na era das antropotécnicas, mas antes nos termos de uma superação a tal ponto radical dos caracteres que nos define como pertencentes à espécie homo sapiens, que aponta para as noções de póshumanidade e transhumanismo.

Diante da vigência irrestrita do imperativo da técnica, segundo o qual o que se pode fazer, deve-se fazer, nossa espécie é convidada e intimada à transcendência inevitável da fatalidade de suas circunstâncias. Com a revolução genômica, o progresso das nanotecnologias, das biotecnologias e do campo da inteligência artificial, franqueou-se o acesso a um território outrora reservado à natureza, isto é, o fundamento da própria natureza humana. Este movimento de conquista do código para a reprojeção de aspectos decisivos de nosso ser próprio nos conduziu às fronteiras da natureza humana, registro no qual vemos dissolver o próprio contorno da categoria "homem". Trata-se agora de perguntar: ainda somos ou até quando seremos meros sapiens? Para onde caminha o evolucionismo? O que a essa altura significa ser humano?

Como indicamos, estas questões explicitam a impotência da categoria do sujeito tradicional em compreender o fenômeno humano face ao virtual fim de uma era, ou seja, para além do horizonte da antropologia humanista. Esta impotência justifica a proposta de superação do humano que aponta não para um conceito reformulado do ser humano, mas para outro conceito relacionado a um novo modo de existência substancialmente diferente, designado como pós-humanidade. Nesse registro, alertamos para o fato de que objetiva-se com a noção de pós-humanidade a construção de um entendimento acerca do fenômeno humano que esteja sintonizado com o desenvolvimento sem precedentes da técnica e seus imperativos. No registro de um imperialismo absoluto da técnica sobre a vida e a cultura humana, busca-se com esta concepção, atualmente em elaboração, a formulação de um recurso interpretativo consistente que não apenas acolha perspectivas e circunstâncias inéditas, mas identifique novas relações ou elementos, ou ainda, que franqueie o acesso a aspectos novos ou aspectos antigos, porém sob novas perspectivas.

É possível que mesmo a conciliação dos componentes humano e animal da natureza humana, i.é., a superação do fosso entre as duas culturas analisado por Snow, parece revelar-se insuficiente para dar conta da hibridação homem e máquina. Suspeitamos que este seja o caso em que a soma dos dois elementos não resulte apenas no conjunto homem mais 
máquina, mas em uma terceira possibilidade. Um terceiro elemento que indicaria um novo modo de existência. De forma que, talvez seja mais frutífero seguir a pista do batesoniano John Brockman que, em franco diálogo com C. P. Snow, inclui em 1995 a noção de uma Terceira Cultura ${ }^{10}$. Nas palavras de Otávio Velho, esta "terceira cultura estaria, sem dúvida, segundo esta visão, assentada no trabalho de pensadores do mundo empírico, que ocupam o espaço dos intelectuais tradicionais" (VELHO, 2010, p. 220).

Esta é a chave de acesso para o movimento de pensamento denominado transhumanista. Jean Guillebaud nos alerta para a importância deste projeto e sua imperdoável marginalização por parte da reflexão acadêmica:

Na Europa, os filósofos clássicos tendem a dar de ombros quando se evoca esta corrente transhumanista. Aos olhos da maioria destes tudo isso não passaria de ficção científica, indigna de uma reflexão séria. (...) Isso é um erro, e temos o direito de deplorar sua desatenção e mesmo sua imprudência. Na realidade, o projeto tranhsumanista - ele se qualifica assim - não é mais coisa do futurismo nem simples delírio. Ele não apenas produziu um corpo de textos quase tão abundante como aquele dos estudos de gênero, mas inspira doravante programas de pesquisa, a criação de universidades especializadas e uma multidão de grupos militantes. Ele influencia uma parcela significativa da administração federal americana e, portanto, o processo de decisão política. Há quase uma década que este projeto, naquilo que o concerne, não está mais confinado ao mundo das ideias. Ele produz o surgimento de lobbies poderosos. As hipóteses que ele propõe não cessam de se alastrar pelas diferentes disciplinas do saber universitário. (GUILLEBAUD, 2011, p.123, tradução nossa).

Através da Declaração Transhumanista ${ }^{11}$ entendemos claramente a proposta de tal projeto:

(1) A humanidade será profundamente afetada pela ciência e tecnologia no futuro. Nós vislumbramos a possibilidade de superar plenamente o envelhecimento, a perda cognitiva, o

\footnotetext{
${ }^{10}$ A obra em questão se chama The third culture: beyond the scientific revolution, e consiste em uma coletânea de textos sobre Bateson e um posfácio escrito por este.

${ }^{11}$ Esta declaração foi assinada em 2002, em um encontro de vinte e quatro integrantes da World Transhumanist Association, organização mais representativa do projeto transumanista. "Fundada em 1998 por Nick Bostrom e David Pearce, a associação congrega atualmente cerca de 15 entidades, possuindo quase quatro mil sócios de uns cem países (2006), e se propõe a servir de plataforma organizacional para os grupos interessados em promover o pós-humanismo. Existem seções em doze países e seus quadros incluem pesquisadores de várias empresas e sociedades científicas (...). O objetivo é livrar o transhumanismo da inconsistência cultural que, segundo seus críticos, possuiria, promovendo sua respeitabilidade acadêmica, moral e intelectual." (RÜDIGER, 2007, p.12-13).
} 
sofrimento involuntário e nosso confinamento no planeta Terra. (2) Acreditamos que o potencial da humanidade ainda não foi realizado. (...) (7) Reivindicamos a legitimidade da escolha pessoal sobre o modo de viver a própria vida. $\mathrm{O}$ que inclui o uso de técnicas que podem ser desenvolvidas para assistir à memória, concentração e energia mental; terapias de extensão da vida; tecnologias reprodutivas de seleção; crionização. (BOSTROM, 2005, p.26, tradução nossa).

Neste registro entende-se a teorização de Hans Moravec, especialista em robótica, sobre a superação do orgânico do ponto de vista interno às tecnociências. Já se trabalha no projeto de viabilização da transferência de nosso "eu" para a máquina. É verdade que Hans Moravec, que juntamente com Marvin Minsky e Eric Drexler integra o time dos principais teóricos do pós-humanismo (RÜDIGER, 2007, p.9), procede a um retorno literal à oposição cartesiana entre corpo e espírito, considerando o primeiro apenas um mecanismo ou locus do segundo. De forma que, estando nossa identidade alocada em nosso espírito, trata-se apenas de desembaraçarmonos do corpo obsoleto a fim de sermos, como os dados facilmente transferíveis entre computadores, transplantados para uma plataforma artificial.

Segundo esta perspectiva, o corpo, considerado um obstáculo a ser superado, é reduzido pejorativamente à "carne"12 perecível e, com isso, dissociado do sujeito cuja existência como sujeito integral passa a ser remetida inteiramente ao registro digital do ciberespaço. Neste paraíso artificial viveríamos como consciência ou cogito puro, puros padrões de informação libertos do peso da matéria, do corpo como injunção de identidade. Possuidor de identidades voláteis, o usuário pode criar incontáveis mundos e formas de encarnação virtual, experimentando uma liberdade sem coerções.

A união do espírito e da máquina corresponde a uma nova forma de existência pós-biológica, isto é, um estágio final de uma evolução que conduzirá ao advento da pós-humanidade ${ }^{13}$. Para Moravec, a era pós-

\footnotetext{
${ }^{12}$ Marvin Minsky, um dos pioneiros da inteligência artificial, descreve o cérebro humano como uma máquina de carne (meat machine) (CLARK, 2001, p.7, tradução nossa).

${ }^{13}$ A ideia de que o progresso tecnocientífico nos conduziu a uma situação totalmente nova, até mesmo potencialmente catastrófica, ou seja, de que estamos na iminência de passar por uma mutação radical e violenta, caracterizada pela absoluta síntese entre homem e máquina, que deixará para trás a humanidade conforme nós a conhecemos, diz respeito a um conceito central ao pensamento pós-humanista, trata-se do conceito de singularidade. $\mathrm{O}$ momento em que se atualizará a singularidade tecnológica é objeto, atualmente, de várias previsões. Segundo Kurzweil, A era das máquinas espirituais (2007) corresponde a um futuro próximo. Até o ano de 2045 será operada a síntese da sensibilidade humana com a inteligência artificial. A fusão da alma com o chip de silício fará desvanecer a linha que separa o homem da máquina, ou a humanidade da tecnologia. Este conceito, por sua vez, é derivado do prognóstico de Irving J. Good que em 1965 previu que em algum momento a
} 
biológica corresponde a "um mundo no qual o gênero humano será varrido por uma mutação cultural e destronado por sua própria progênie artificial" (MORAVEC, 1988 apud BRETON, 2003, p.127). A ideia central é que a existência humana encarnada se tornou obsoleta, incapaz de se adaptar ao ambiente técnico e informativo que a própria espécie humana criou ${ }^{14}$.

Segundo Joel Garreau (2006), o núcleo comum a esta rede corresponde à crença de tal forma radical na engenharia evolutiva de póshumanos a ponto de estes não mais serem considerados inequivocamente humanos como suas edições convencionais. A vida é de tal forma reconfigurada pelas biotecnologias, que a otimização ilimitada interfere no processo evolutivo instituindo uma outra via (virtual) da evolução humana. A categoria "transhumano" corresponderia, portanto, àqueles que estão em processo de se tornar pós-humanos, ou melhor, em trânsito.

Porém, Katherine Hayles questiona a pretendida ruptura reivindicada pelo movimento transhumanista face ao núcleo de sentido comum que designa o humanismo. Segundo esta autora:

Quando Moravec imagina "você" escolhendo fazer download de si mesmo para um computador, desse modo obtendo através do domínio tecnológico o privilégio último da imortalidade, ele não está abandonando o sujeito autônomo liberal, mas expandindo suas prerrogativas ao reino do pós-humano. Contudo, o pós-humano precisa não ser recuperado retomando um humanismo liberal, tampouco ser construído como antihumanismo. Localizado dentro da dialética do patriarcado e fundado na atualidade incorporada em vez da informação imaterial, o pós-humano oferece recursos para repensar a articulação entre humanos e inteligência artificial. (HAYLES, 1999, p.287, tradução nossa, grifo nosso).

Michael Sandel (2013), também problematiza o tratamento do problema da identidade humana na atual era da engenharia genética em termos do individualismo liberal, mergulhado em sua ficção de perfectibilidade $^{15}$. Ao passo que Nick Bostrom, mostra claramente como este sentido de pós-humanismo, isto é, o transhumanismo, deriva diretamente dos ideais de perfectibilidade, racionalidade e intencionalidade

inteligência artificial alcançaria o mesmo padrão de sofisticação cognitiva da inteligência humana e logo superaria seus criadores institucionalizando o primado do pós-humano.

${ }^{14} \mathrm{O}$ corpo "por um lado, é esmagado pela velocidade, pela precisão e pelo poder da tecnologia; por outro, é submergido pela quantidade e pela complexidade das informações acumuladas." (BRETON, 2003, p.126).

${ }^{15}$ Ficção que tem origem na reivindicação humanista do direito especial do ser humano em "determinar-se conforme o próprio arbítrio" (MIRANDOLA, 1986, p.52). Também Teilhard de Chardin se declara favorável a um autoaperfeiçoamento do homem, inclusive em relação à aparição de um possível "tipo humano superior". Segundo Chardin, isso nos faria "ajudar Deus" (CHARDIN, 2002 apud GUILLEBAUD, 2011, p.127). 
humana herdados do humanismo renascentista e esclarecimento (WOLFE, 2010, p.xiii).

\begin{abstract}
A herança do Renascimento combina com a influência de Isaac Newton, Thomas Hobbes, John Locke, Immanuel Kant, o Marquês de Condorcet e outros, para formar a base do humanismo racional, o qual enfatiza a ciência empírica e a razão crítica - ao invés da revelação e autoridade religiosa como modos de conhecer o mundo natural e nosso lugar nele e fornecer um fundamento para a moralidade. Transhumanismo tem origem no humanismo racional. (BOSTROM, 2005, p.2-3, tradução nossa).
\end{abstract}

A dificuldade de se distinguir claramente humanismo e póshumanismo, ou seja, de avaliar se há de fato uma ruptura significativa em relação ao paradigma de interpretação da experiência humana da perspectiva humanista, deve-se, em grande parte, ao fato de que, diferentemente do humanismo cuja pluralidade de expressões pode ser remetida a um núcleo de sentido comum, o pós-humanismo reúne definições diferentes e irreconciliáveis (WOLFE, 2010, p.xi). O objetivo de Cary Wolfe ao mapear as permutas entre humanismo e pós-humanismo é evitar que o debate gire em torno de um humanismo pós-humanista ou de um pós-humanismo humanista. Com isto, ele fornece importantes recursos para avaliar a especificidade da reflexão pós-humanista, bem como alerta para vestígios do paradigma humanista nas teorizações de autores considerados póshumanistas. Segundo Wolfe,

quando falamos sobre pós-humanismo, não estamos falando apenas sobre temas da ética de descentralização do humano em relação a uma ou outra coordenada evolucionária, ecológica ou tecnológica (embora seja onde a conversa usualmente inicia e, frequentemente, termina); antes, eu quero insistir em que nós estamos falando também sobre como pensaremos o confronto com essa temática, que pensamento emerge em face destas mudanças. (WOLFE, 2010, p.xvi, tradução nossa, grifo do autor).

Assim, nossa hipótese é que Moravec, juntamente com outros apóstolos da desmaterialização, como Ray Kurzweil, pertenceriam a um dos filamentos do pós-humanismo, o transhumanismo. Para estes seria catastrófico que as vantagens prometidas pela técnica não se materializassem devido à tecnofobia ou proibições inúteis. Nos escritos de Kurzweil vemos uma profissão de fé inflamada em nome da liberdade de remodelar sua própria espécie (e nisso ele toma ao pé da letra a discurso de Mirandolla acerca do direito natural do homem ser o que ele escolhe ser) rejeitando qualquer tipo de limite e proibição que, em nome da prudência ou da ética impediria o homem de ir além (GUILLEBAUD, 2011, p.127). 
Segundo Cary Wolfe, a especificidade do pensamento pós-humanista estaria antes na necessidade de se elaborar um novo paradigma teórico capaz de interpretar os diversos aspectos, implicações e significados envolvidos no processo de intervenção tecnológica no homem ${ }^{16}$. É nesse sentido que se deve ler a passagem:

Meu sentido de pós-humanismo é, desta maneira, análogo à interpretação paradoxal do pós-moderno feita por Lyotard: ao mesmo tempo anterior e posterior ao humanismo: anterior no sentido que denomina a incorporação e integração do ser humano não apenas no seu mundo biológico, mas também no mundo tecnológico, a coevolução artificial do animal humano com a tecnicidade das ferramentas e mecanismos externos de armazenamento (como a linguagem e cultura) da qual Bernard Stiegler provavelmente permanece nosso mais persuasivo e ambicioso teórico - e tudo o que antecede esta historicamente específica coisa chamada "o humano" que a arqueologia de Foucault investiga. Mas posterior no sentido que póshumanismo designa um momento histórico em que o descentramento do humano por meio de sua imbricação nas redes (técnica, médica, informática e econômica) é cada vez mais impossível ignorar, um desenvolvimento histórico que nos aponta em direção à necessidade de um novo paradigma teórico (mas também nos impele a ele), um novo modo de pensamento que vem depois das repressões culturais e fantasias, do protocolo filosófico e evasões, do humanismo como um fenômeno historicamente específico. (WOLFE, 2010, p.xv, tradução nossa, grifo nosso).

O tema da descentralização nos conduz ao cerne da oposição entre humanismo e pós-humanismo, assim como nos indica a potencialidade da reflexão antropológica e, sobretudo, ética, do pensamento pós-humanista. Entende-se por descentralização um olhar sobre a experiência humana não determinado pela sublimação ou elevação de determinadas experiências culturais ao nível de pretensas definições antropológicas universais. Sob o viés do humanismo a antropologia é convertida em andrologia (PARÍS, 2002, p.37 ${ }^{17}$. Ofusca-se, assim, a possibilidade de acolher e interpretar a o

\footnotetext{
${ }^{16}$ Ora, "se o homem só existe por meio das formas corporais que o colocam no mundo, qualquer modificação de sua forma implica uma outra definição de sua humanidade", de forma que "uma desordem introduzida na configuração do corpo é uma desordem introduzida na coerência do mundo." (BRETON, 2003, p.136).

${ }^{17}$ A crítica ao antropocentrismo ontológico do humanismo fundado em uma forma perfeita, substancial, autoreferenciada, dar-se-á, sobretudo, mediante a valorização da alteridade. O pós-humanismo revela-se, assim, não como celebração do humano como senhor e possessor da natureza, mas como celebração do papel constitutivo da hibridação na identidade. Segundo Marchesini, nós realizamos as nossas qualidades nos antropodescentrando-nos, isto é, assumindo outras perspectivas. De forma que o enfoque conjugativo do pós-humanismo retoma o caráter relacional do humano. Critica-se a ideia de uma subjetividade normativa, que aponta para um conceito específico de humano (homem,
} 
que para o pós-humanismo corresponde à principal característica que redefine o humano na era das tecnociências: a abertura radical à alteridade nesta era de convergência e hibridação irreversível entre humano e máquina.

Procede-se simultaneamente, "de um lado à mecanização e eletrificação do humano; de outro, a humanização e subjetivação da máquina", de forma que, "da combinação desses processos que nasce a criatura pós-humana a que chamamos 'ciborgue'." (TADEU, 2000, p.12). Tal figura, a quintessência da tecnologia, representa o grande desafio interposto pelo pós-humanismo ao outrora insuspeito antropocentrismo ontológico do humanismo. Segundo Tomaz Tadeu (2000, p.11), a realidade do ciborgue põe em xeque a ontologia do humano, obriga-nos a deslocá-la, pois, diante da impossibilidade de distinguir onde termina o humano e onde começa a máquina, ela nos intima não à pergunta sobre a natureza das máquinas, mas dos humanos. $\mathrm{O}$ núcleo problemático da existência de uma criatura híbrida tecno-humana que simula o comportamento humano, mas cuja ação não pode ser remetida a nenhuma interioridade, essencialidade ou racionalidade, porque feita de fluxos e circuitos, fios e silício, situa-se na dúvida que ela suscita acerca da própria singularidade e exclusividade do humano.

Saber o que os ciborgues são, segundo Donna Haraway, é uma questão radical, pois diz respeito às nossas condições de sobrevivência. Em seu mais famoso ensaio, Manifesto ciborgue, Haraway argumenta em favor da promiscuidade ontológica que doravante define o humano, do prazer da confusão de fronteiras e da responsabilidade política em sua construção, além, é claro, de contribuir para a teoria e cultura socialista-feminista.

Estou argumentando em favor do ciborgue como uma ficção que mapeia nossa realidade social e corporal e também como um recurso imaginativo que pode sugerir alguns frutíferos acoplamentos. O conceito de biopolítica de Michel Foucault não passa de uma débil premonição da política-ciborgue - uma política que nos permite vislumbrar um campo muito mais aberto. [... ] O ciborgue é nossa ontologia; ele determina nossa política. O ciborgue é uma imagem condensada tanto da imaginação quanto da realidade material: esses dois centros,

branco, europeu etc.) mergulhado no mito de sua própria pureza antrópica, i.é., separado do restante da natureza e das outras espécies animais, porque nesta ideia encontramos a base de toda forma de discriminação. Não por acaso, o operador discriminativo sempre apelou à natureza zoomorfa do discriminado: o louco, a mulher, o negro, o índio, a criança, o deficiente etc., todos estes representados como animais ou dotados de maior dose de animalidade (MARCHESINI, 2006, não paginado). Por isso, parte importante do debate pós-humanista advém de vozes críticas do racismo (BALIBAR), sexismo (HARAWAY) e especismo (SINGER), dentre outros. Se a crítica ao ideal humanista do homem com único protagonista do universo, de fato, puder ser considerada um núcleo de sentido comum ao pós-humanismo, restaria não apenas avaliar a consistência e legitimidade desta crítica, mas também analisar pontualmente o pensamento de cada autor, a fim de averiguar se ele carrega vestígios do humanismo, para considerá-los ou não pós-humanistas. 
conjugados, estruturam qualquer possibilidade de transformação histórica. (HARAWAY, 2000, p.37).

O que autoriza este posicionamento é a formulação de um entendimento do "sujeito" em termos do pensamento cibernético ${ }^{18}$, isto é, não mais definido em relação à sua humanidade ou animalidade, mas enquanto padrões de informação. Tal é o fundamento para a consolidação da ideia do humano como um ser que se autoconstrói, na medida em que possui o princípio de sua própria determinação. Esta reformulação se inscreve no contexto da pesquisa de um novo modelo teórico para processos biológicos, mecânicos e comunicativos que removeram o Homo sapiens de sua posição privilegiada em relação a questões de significado, informação e cognição. Reinscrevendo o humano, assim como a natureza e a tecnologia em um registro comum.

Outro recurso conceitual elaborado pelo pensamento pós-humanista para a compreensão deste desvanecimento de fronteiras corresponde à realidade da convergência tecnológica ${ }^{19}$. Este conceito permite compreender a subjetividade polimórfica reivindicada por Haraway ao ciborgue, assim como a reivindicação do pensamento pós-humanista da aposentadoria das tradicionais oposições entre natureza e cultura, natural e artificial, biológico e social. Ratificar a superação do pensamento dicotômico próprio ao

\footnotetext{
18 A pergunta pelo contexto de surgimento do pensamento cibernético nos remete especialmente às Conferências Macy sobre Cibernética (1943-1954), que reuniu especialistas de diversos campos em torno do tema "Mecanismos de retroalimentação e sistemas de causação circular em sistemas biológicos e sociais". Duas visões do homem foram postas em discussão: a primeira o definia em termos de mecanismo homoestático auto-regulado, ao passo que a segunda o concebia como ponto de passagem de um circuito de informações (HAYLES, 1999, p. 50-83). Deste duelo impôs-se a compreensão cibernética do ser humano explicitada, sobretudo, por Norbert Wiener. Fundador da teoria da informação, Wiener remete a definição da experiência humana à categoria central de informação. Segundo ele, "Informação é o termo que designa o conteúdo daquilo que permutamos com o mundo exterior ao ajustar-nos a ele, e que faz com que nosso ajustamento seja nele percebido. O processo de receber e utilizar informação é o processo de nosso ajuste às contingências do meio ambiente e de nosso efetivo viver nesse meio ambiente." (WIENER, 1968, p.17-8). A própria noção de ciborgue (organismo cibernético) é oriunda dos textos de Wiener.

${ }^{19}$ Segundo Guillebaud (2011, p.123), o conceito de convergência tecnológica é uma das duas ideias fundadoras do programa transhumanista, ao lado do conceito de singularidade. A convergência tecnológica já não é mais simples teoria, mas foi o objeto de um relatório dirigido pela National Science Foundation (NSF) e o Department of Commerce (DOF). "O objetivo deste relatório estava explícito: melhorar as performances humanas (Improving Human Performance). O estabelecimento desta relação mobilizou dezenas de pesquisadores. Pretendia-se esclarecer a situação em que se encontra o avanço das quatro tecnologias mais promissoras: nanotecnologias, biotecnologias, informática e ciências cognitivas. Por esta razão o texto de quatrocentas páginas entrou para a história sob a abreviatura NBIC, sigla representando a inicial de cada tecnologia citada. O tema central é sobre uma irresistível - e desejável - convergência entre estas diversas tecnologias". (GUILLEBAUD, 2011, p.123-4, tradução nossa).
} 
humanismo racional é uma das questões nucleares ao pensamento póshumanista. A ontologia do ciborgue elaborada por Haraway constitui um dos esforços mais populares nesse sentido.

Através deste breve percurso que foi da ontologia humanista à ontologia pós-humanista, abordando inclusive alguns aspectos e referenciais importantes que compõem o heterogêneo campo de reflexão pós-humanista, indicamos alguns aspectos importantes para a recolocação da questão acerca do significado de ser humano. O deslocamento desta questão se tornou inevitável à medida que conquistamos um grau de autodeterminação inimaginável até pouco tempo atrás, assim como gerou um efetivo e generalizado mal estar antropológico. É natural que, como salienta Michael Sandel, "quando a ciência avança mais depressa do que a compreensão moral, como é o caso de hoje, homens e mulheres lutam para articular seu mal-estar" (2013, p.22). O problema é que o vocabulário forjado pelas sociedades liberais, centrado nos conceitos de autonomia, justiça e direitos humanos, e poderíamos acrescentar, de identidade, dignidade e subjetividade humana, "não nos equipou para abordar temas mais difíceis colocados pelas práticas de clonagem, crianças projetadas e engenharia genética. Razão pela qual a revolução genômica induziu a uma espécie de vertigem moral" (SANDEL, 2013, p.22). Nas suas palavras, "para compreender a ética do melhoramento, precisamos enfrentar questões que há muito se ausentaram do campo de visão do mundo moderno - relativas ao estatuto moral da natureza e à atitude adequada dos seres humanos em relação ao mundo "dado" (SANDEL, 2013, p.23). São essas as questões de fundo que, implícita ou explicitamente, estão envolvidas na discussão póshumanista acerca do significado do conceito de ser humano.

Dentre as principais contribuições do pensamento pós-humanista que abordamos ao longo do artigo, sublinharemos na passant as duas mais expressivas. Em primeiro lugar, o projeto da inteligência artificial que prevê a concretização das condições de viabilidade para a transferência da consciência para a máquina reacende o debate acerca do estatuto da corporeidade humana. Trata-se de saber se, como afirmam teóricos como Moravec ou Minsky, o corpo é meramente um locus ou substrato prescindível à nossa existência como sujeitos integrais ou, ao contrário, o corpo é um aspecto de nosso ser e de nossa identidade absolutamente necessário. Este debate pressupõe o diálogo entre a tradição filosófica e possibilidades técnicas e, como tal, ainda se encontra em discussão. O segundo aspecto relevante que os autores pós-humanistas recolocam em pauta é a necessária superação do abismo entre ciências naturais e humanidades, entre tecnociências e atividade reflexiva. A discussão acerca do solo comum em que conversarão e se afetarão mutuamente disciplinas como antropologia, ciências sociais e política, psicologia e psicanálise dentre outras e ciências como engenharias, medicina, inteligência artificial, tecnologias da informação e da computação para citar alguns exemplos, é 
nuclear à reflexão acerca do novo estatuto da relação entre humanidade e tecnologias e, também está em pauta atualmente. Trata-se de uma discussão fundamentalmente metodológica em relação à qual a reflexão filosófica não pode abster-se.

Assim, nossa proposta neste artigo foi articular alguns elementos importantes acerca da necessidade de se pensar um novo modo de tratamento para novos problemas na atual era tecnocientífica, avaliando essa novidade em termos de ruptura ou continuidade com a tradição humanista.

\section{Referências bibliográficas}

BALIBAR, E. Racismo y nacionalismo. In: ; WALLERSTEIN, I. Raza, nación y clase. Madri: IEPALA, 1991. p.63-111. BENDASSOLLI, P.F. A Psicologia Revisitada pela Pragmática: Subjetividade, Conhecimento e Método. Psicologia: Reflexão e Crítica, Porto Alegre, v.15, n. 2, p. 309-319, 2002.

BOSTROM, Nick. A history of transhumanist thought, 2005. Disponível em: <http://www.nickbostrom.com/papers/history.pdf>. Acesso em: 8 ago. 2014. p.1-30.

BRETON, D. Adeus ao corpo. In: NOVAES, A. (Org.). O homem-máquina: a ciência manipula o corpo. São Paulo: Companhia das Letras, 2003. p. 123137.

BROCKMAN, J. The Third Culture: beyond the scientific revolution. London: Simon \& Schuster, 1995.

CLARK, A. Mindware. New York: Oxford University Press, 2001.

DESCARTES, R. Discurso do método. São Paulo: Martins Fontes, 1996.

FEENBERG, A. O que é filosofia da tecnologia? 2003. Disponível em: <http://www.sfu.ca/ andrewf/oquee.htm>. Acesso em: 13 abr. 2015. Não paginado.

FERRY, L; RENAUT, A. Pensamento 68. São Paulo: Ensaio, 1989.

FOUCAULT, M. As palavras e as coisas. São Paulo: Martins Fontes, 1999.

GARREAU, J. Radical Evolution. New York: Broadway Books, 2006.

GUILLEBAUD, Jean-Claude. La vie vivante. Paris: Éditions des Arènes, 2011

HARAWAY, D. Manifesto ciborgue. In: TADEU, T. (Org.). Antropologia do ciborgue. Belo Horizonte: Autêntica, 2000. p. 33-118.

HAYLES, K. N. How we became posthuman: virtual bodies in cybernetics, literature, and informatics. Chicago: The University of Chicago Press, 1999.

INGOLD, T. Humanidade e animalidade. Revista Brasileira de Ciências Sociais, São Paulo, v. 28, p. 1-15, jun. 1995.

KANT, I. Crítica da faculdade do juízo. Rio de Janeiro: Forense Universitária, 2012.

KURZWEIL, R. A era das máquinas espirituais. São Paulo: Editora Aleph, 2007. 
MARCHESINI, R. O pós-humanismo como ato de amor e hospitalidade. Revista do Instituto Humanitas da Unisinos, São Leopoldo, edição 200, ano VI, 2006. Entrevista concedida a IHU on-line. Disponível em: <http://www.ihuonline.unisinos.br/index.php?option=com_content\&view=a rticle\&id=494\&secao=200>. Acesso em: 13 abr. 2015. Não paginado.

MIRANDOLA, G. P.D. Discurso sobre a dignidade do homem. Rio de Janeiro: Edições 70, 1989.

ONU, BRASIL. Declaração Universal dos Direitos Humanos. Disponível em: <http://unesdoc.unesco.org/images/0013/001394/139423por.pdf >. Acesso em: 8 ago. 2014.

PARÍS, Carlos. O animal cultural. São Carlos, EdUFSCar, 2002.

ROSE, N. Inventando nossos eus. In: TADEU, Tomaz T. (Org.). Nunca fomos humanos: nos rastros do sujeito. Belo Horizonte: Autêntica, 2001. p. 137-204.

RÜDIGER, F. Breve história do pós-humanismo: elementos de genealogia e criticismo. E-Compós. Brasília, v. 8, 2007, p.2-17. Disponível em: $<$ http://www.compos.org.br/seer/index.php/ecompos/article/view/145/146>. Acesso em: 13 abr. 2015.

SANDEL, Michael J. Contra a perfeição. Rio de Janeiro: Civilização Brasileira, 2013.

SNOW, C.P. The two cultures and the scientific revolution. New York: Cambridge University Press, 1959.

SPINOZA, B. Ética. Trad. Tomaz Tadeu. Belo Horizonte: Autêntica Editora, 2010.

TADEU, T. Nós, ciborgues. O corpo elétrico e a dissolução do humano. In: TADEU, T. (Org.). Antropologia do ciborgue. Belo Horizonte: Autêntica, 2000. p. 7-15.

VELHO, O. Os novos sentidos da interdisciplinaridade. Mana, Rio de Janeiro, v.16, n. 1, 2010, p.213-226. Disponível em: <http://www.scielo.br/pdf/mana/v16n1/a09v16n1.pdf >. Acesso em: 13 abr. 2015.

WIENER, N. Cibernética e sociedade. São Paulo: Cultrix, 1968.

WOLFE, C. What is Posthumanism? London: University of Minnesota Press, 2010. 